\title{
Mulheres negras e Necropolítica: como enfrentam a morte de seus filhos?
}

\author{
Black women and Necropolitics: how \\ they face the death of their children?
}

\author{
Leticia Gomes Souza' 1 \\ Marilda Castelar ${ }^{2}$ (1) \\ Karine de Souza Oliveira Santana ${ }^{3}$ (1) \\ Verena Souza Souto ${ }^{4}$ (1)
}

\author{
1Autora para correspondência. Escola Bahiana de Medicina e Saúde Pública (Salvador). Bahia, Brasil. leticiasouza15.2@bahiana.edu.br \\ ${ }^{2,3}$ Escola Bahiana de Medicina e Saúde Pública (Salvador). Bahia, Brasil. marildacastelar@bahiana.edu.br, karinesantana@bahiana.edu.br \\ ${ }^{4}$ Centro Universitário UniFTC (Salvador). Bahia, Brasil. verena.souto@gmail.com
}

RESUMO | OBJETIVO: A morte de jovens negros é o principal resultado da violência urbana. Quando esses jovens morrem deixam os seus familiares, principalmente as mães negras, em um contexto de sofrimento causado por essa perda. Nesse contexto, as mulheres negras desenvolvem formas de enfrentamento para lidar com a dor. OBJETIVO: Analisar formas de enfrentamento de mulheres negras diante do assassinato de seus filhos na capital baiana. MÉTODO: Trata-se de uma pesquisa qualitativa, do tipo documental, realizada em sites que publicaram relatos dessas mulheres entre 2014 a 2019. Os dados foram analisados a partir da análise de conteúdo, com fundamento em Minayo. Para a realização da pesquisa, fez-se o uso de documentos públicos e de acesso livre. RESULTADOS: Foram mapeados oito relatos de mães negras, sendo sete oriundos de jornais online e um em blog. Seus relatos revelam muito sofrimento psíquico, e desvelam contextos marcados por racismo, violências e violação de direitos. Nesse cenário emergiram algumas formas de enfrentamentos como a religiosidade, a busca por justiça e a percepção das mães negras diante do racismo. CONSIDERAÇÕES: Foi possível conhecer a caminhada dessas mulheres que foram atravessadas pela violência e que a partir disso construíram formas de enfrentamento e cuidado. Os resultados apontam para maior necessidade de pesquisas que investiguem mais sobre esse sofrimento e seus desdobramentos na saúde mental dessas mães.

PALAVRAS-CHAVE: Racismo. Necropolítica. Mulheres negras. Genocídio. Mães.
ABSTRACT | OBJECTIVE: The death of young black people is the main result of urban violence. When these young people die they leave their families, especially black mothers who needs to deal with the pain. OBJECTIVE: To analyze ways of confronting black women in the face of the murder of their children in Salvador. METHOD: This is a qualitative documentary research carried out on websites that published reports of these women between 2014 and 2019. The data were analyzed from content analysis, based on Minayo.To carry out the research, public documents and free access were used. RESULTS: Eight reports of black mothers were mapped, seven from online newspapers and one from blog. These reports reveal much psychic suffering, and reveal contexts marked by racism, violence and violation of rights. In this scenario, some forms of confrontations emerged, such as religiosity, the search for justice and the perception of black mothers in the face of racism. CONSIDERATIONS: It was possible to know the walk of these women who were crossed by violence and and that from this they built ways of coping and care. The results point to a greater need for research that investigates more about this suffering and its consequences in the mental health of these mothers.

KEYWORDS: Racism. Necropolitics. Black women. Genocide. Mothers. 


\section{Introdução}

A violência urbana no Brasil é crescente e alarmante. Segundo o Atlas da Violência de 2019 e 2020, houve um aumento significativo nos homicídios entre jovens negros do sexo masculino, que tinham entre 15 a 29 anos (Instituto de Pesquisa Econômica Aplicada, 2019; 2020).

Para Costa, Ndjaine \& Sckenker (2017) as mortes de jovens por assassinato têm características diferentes de outros tipos de mortes, trazendo à tona uma perda violenta, repentina, brusca e prematura, o que impacta nas respostas em relação ao luto, gerando sentimentos de incompletude e raiva. Nesse contexto temos os familiares, com destaque para as mães que vivem esse processo. O contato com a dor da perda provoca reações psíquicas de sofrimento e lembranças dolorosas, pois essa morte é a concretização de uma interrupção do ciclo da família. Como essas mortes são atravessadas por questões sociais, o apoio às famílias pode ser insuficiente e até inexistente, causando isolamento e maior sofrimento

Dois componentes aparecem dentro do processo de perda. O primeiro, sendo a mídia, que pode ter o papel de potencializar a dor e o sofrimento a partir do que é divulgado, ou então ajudar na busca por justiça. $E$, o segundo sendo a religiosidade que proporciona amparo e reestruturação dessas mães (Alarcão, Carvalho \& Pelloso, 2008).

Em relação a produções de estudos sobre esse processo de perda no qual as mães negras vivenciam, Araújo e Argolo (2017) apontam que existe a necessidade de se produzir mais sobre essas mulheres dentro desse contexto. É perceptível que exista uma baixa produção de pesquisas sobre essa temática, principalmente trazendo a discussão racial articulada com maternidade, violência urbana e juventude.

Existe um contexto de invisibilidade da mulher negra tanto em produções acadêmicas, quanto em outros espaços de discussões, como no feminismo. Assim, a exposição a violações e negação de diretos, reflete o que Piedade (2017) discute sobre o quanto o racismo coloca essa mulher em um lugar marcado de ausência histórica, que perdura até os dias atuais.

São nessas dores vivenciadas pela mulher negra, que Piedade (2017) apresenta o termo Dororidade, que vem da palavra dor e que está ligada a dor que une as mulheres negras por vivenciarem diversos sofrimentos em suas trajetórias. Essa dor é sobre a dor da perda, da escravidão, do machismo e do racismo (Piedade, 2017).

Na área da Psicologia, a produção de pesquisas sobre a mulher negra ainda é insuficiente, demostrando o quanto as pesquisas científicas ainda estão aquém de discutir a intersecção raça, gênero, classe e geração. Levar essas discussões para além da individualização e patologização dos fenômenos sociais são um caminho ainda pouco trilhado pela Psicologia. Essa insuficiência é demostrada a partir do estudo feito pelas autoras Damasceno e Zanello (2018), que discutiram sobre a pouca quantidade de pesquisas que tratam da saúde mental da população negra, e mais diretamente da mulher negra.

A baixa quantidade de produções científicas, é resultado de todo o processo da escravidão e pós-escravidão que as mulheres negras vivenciaram no Brasil, no qual grande parte das investigações acadêmicas partem de pesquisadores que negam o papel do racismo como estruturante da subjetividade e que interfere na saúde mental e vida da população negra.

O estudo de Santiago (2019) identifica o quanto as muIheres negras são atravessadas pela violência urbana em seus territórios, que transforma esses espaços em um campo de guerra. Também são nestes lugares que surgem os movimentos de resistência, principalmente pelas mães que tiveram seus filhos assassinados.

Como visto, é possível relacionar a tragédia social da violência com a Necropolítica, que funciona em direção a inscrição de corpos negros dentro do processo de morte. Assim Mbembe (2018) nos apresenta o conceito de Necropolítica como formas de submeter a vida ao poder da morte, ou seja, são configurações que determinam qual corpo deve morrer. 
O Estado, é um dos mecanismos que fazem parte da configuração da Necropolítica. Ela é uma organização polimorfa e difusa, trazendo como proposta o direito de matar. Assim, temos como exemplo a guerra, o discurso do medo e a construção de inimigos como as principais tecnologias que perpetuam o exercício do matar.

Nesta lógica, Barros et al (2019) aborda a discussão de Mbembe (2018) dentro do contexto brasileiro, demostrando que existem, para a população negra no Brasil, configurações que inscrevem seus corpos dentro do discurso do terror e os direcionam para a morte, sendo sentida e presenciada em vida. Esse processo pode ser ilustrado com a constante exposição da população negra a guerras que acontecem dentro das periferias.

Nesse contexto, a violência pode ser vista como um necropoder que perpetua o genocídio do povo negro (Damasceno \& Zanello, 2018; Dupas \& Romero 2018). Desvelando o quanto a violência e o racismo caminham juntos. Sendo uma temática relevante para a compreensão de como essas relações interferem em aspectos intrapsíquicos, permitindo uma atuação da psicologia alinhada com aspectos históricos e sociais da população negra.

Dialogando com o que Davis (2016) apresenta em sua obra Mulheres, Raça e Classe, é possível relacionar sobre a posição da mulher negra e o legado da escravidão no Brasil. Pois, como uma releitura do modelo escravista, a violência chega para separar novamente essas mães dos seus filhos. Mas existem a ressignificação e resistência por parte dessas mulheres negras com as suas maternidades.

Assim, na contramão das estruturas sociais que negam esses processos de sofrimento, as mães desses jovens podem desenvolver formas de lidar com a exposição constante das mortes. O compartilhamento das experiências sobre violência e violações são territórios possíveis para ressignificação, cuidado e enfrentamento. Assim, o presente artigo analisa quais são as estratégias utilizadas por essas mulheres negras diante do assassinato de seus filhos na capital baiana.

\section{Mulher, Racismo e Necropolítica}

A história da população negra brasileira é marcada pelo grande rastro de violência, demostrando que essas marcas do passado ainda são presentes para esse povo. Assim, a reparação da dívida social e histórica de séculos de sofrimento ainda é lenta em comparação com décadas de exclusão e negação (Fernandes \& Souza, 2016).

Deste modo, o racismo, que se configura como um fenômeno constituinte da experiência histórica, social, comportamental e subjetiva, tem a função estruturante de reafirmar o privilégio branco à custa da população negra, então, nesse lugar de exclusão, restam poucas possibilidades de pertencimento e ascensão (Conselho Federal de Psicologia, 2017).

Para além de uma dimensão individual e que culpabiliza apenas as pessoas, é importante reconhecer o racismo enquanto algo que extrapola as relações interpessoais dos sujeitos, para não reduzir o racismo como apenas um fenômeno individual, pontual, moralista e patológico.

Assim, seguimos o pensamento de Almeida (2018) que discute o racismo para além da questão do comportamento individual. Conceituando o racismo em três dimensões, sendo a primeiro o racismo individual, a segunda como o racismo institucional que tem as instituições como produtoras e mantenedoras desses comportamentos individuais, influenciando em aspectos políticos, econômicos e sociais

E racismo estrutural, no qual atribui que uma sociedade desenvolve uma ordem social que privilegia um grupo em detrimento de outro, construindo práticas sociais que se repetem na dimensão institucional e também impactando no individual. Assim, o Racismo Estrutural e Institucional são os propulsores das diversas violências contra a população negra. Essas diversas dimensões, impactam em aspectos biopsicossociais (Almeida, 2018). 
A Necropolítica e o Racismo caminham juntos, perpetuando de forma explícita e letal o extermínio da população negra, que se encontra, ao longo de séculos, excluídas e marginalizadas dentro de periferias, vivendo em precárias condições socioeconômicas, sanitárias e de segurança (Longo, 2012).

São nesses territórios que a mulher negra sobrevive, e tem a sua subjetividade atravessada por essa vivência constante com a violência. Agravando ainda mais esse cenário, Akotirene (2019) nos reafirma o que outras autoras já apontam, de que o racismo caminha junto com o machismo, que também faz parte desse processo e potencializa o silenciamento e desprestigio do sofrimento das mulheres negras, contribuindo para a invalidação da sua busca por ajuda.

Sendo o Brasil um país com profundas desigualdades sociais e raciais, é possível perceber que jovens negros têm poucas possibilidades de emprego, moradia, saúde, segurança pública. Restando poucas possibilidades de existência e pertencimento social, tendo como alternativa mais acessível a vinculação com o tráfico de drogas (Faria, Barros \&Andrade, 2011). Essa exposição à realização de atividades ilícitas, é um potencializador da aproximação de situações ameaçadoras e letais.

Como resultado, os últimos Atlas da Violência demostram o aumento de homicídios de jovens negros e a reafirmação da desigualdade racial. Neste contexto de violência, os principais motivos dessas mortes giram em torno de confrontos pelo tráfico de drogas, brigas e outras condutas. Neste sentido, os jovens negros apresentam 3,3\% mais chance de serem assassinados do que um jovem não negro (IPEA, 2019; 2020).

A Bahia ocupa atualmente o quinto estado com mais homicídios no país. O panorama atual mostra que a população negra representa $75,7 \%$ das mortes violentas no Brasil, enquanto as taxas por essas mesmas mortes em não negros vem diminuindo exponencialmente (IPEA, 2020)

O resultado de tantos homicídios, são atravessados, principalmente, pelo discurso da Guerra às Drogas, em que são criados inimigos passíveis de serem exterminados, e consequentemente são desenvolvidas tecnologias para conter e reprimir o tráfico, e com isso o corpo que mais sofre e morre, direta ou indiretamente, é o corpo negro (Santiago, 2019).
Assim, o jovem negro é colocado em uma situação de vulnerabilidade, sendo tratado como apenas um corpo que produz perigo urbano (Machado \& Noronha, 2002) e, por esse motivo, precisaria ser exterminado.

A violência policial nas periferias sempre foi presente e vem crescendo deliberadamente. Chacinas e operações que resultaram na execução e morte de jovens estampam as grandes mídias e anunciam o genocídio progressivo desse povo. Entretanto os dados são subnotificados e há uma lacuna em relação a registros de mortes causadas por intervenções policiais (IPEA, 2018; 2019).

Santiago (2019) discute a naturalização das mortes nos territórios periféricos. Sendo este viabilizado pelo Estado e realizado por meio da violência policial com potencial de alta letalidade. Assim, a periferia que sempre foi território de existência da população negra, torna-se um espaço aberto para o seu extermínio. Essa organização dos mecanismos de extermínio, que no Brasil ganha contorno através das guerras nas periferias, está alinhada com os discursos e estereótipos sociais que naturalizam e autorizam o extermínio.

Nesta configuração, temos o retrato concreto da necropolítica proposto por Mbembe (2018) que afirma o terror e o medo como características importantes para a construção do inimigo matável.

A mulher negra, que está inscrita socialmente em um lugar de subordinações, opressões, violações e desvalorização (Madeira \& Gomes, 2018), além de sofrer com isso, também padece enquanto mãe silenciada pelo Estado, mídia e sociedade diante da morte do seu filho. Desta forma, percebe-se que a morte e o luto são fenômenos sociais e políticos (Alencar, 2011).

Para Gonçalves e Bittar (2016) o luto é um processo necessário para a acomodação da perda. Mas, para os mesmos autores, o processo de elaboração do luto é uma tarefa bastante complexa dentro do contexto de violência.

Domingues, Fontoura, Dessen \& Queiroz (2015) ao realizarem estudos sobre perda por mortes violentas perceberam que no caso da população negra, existem evidências de um maior contato com a perda por homicídio. Porém, poucos buscam pela rede de cuidado a saúde mental. Para os autores, o povo negro tende a recorrer a redes informais de 
cuidados, como os coletivos ou instituições religiosas para elaboração da perda.

Há um contexto histórico que ganha novos contornos na contemporaneidade, como apontam Davis (2016) e Akotirene (2019) ao discutirem sobre com a mãe negra foi marcada por um percurso de exposição a processos de perda dos seus filhos que vem desde a escravidão, quando essas mães eram estupradas e utilizadas apenas como reprodutoras, sendo apartadas de suas crianças para que estas fossem posteriormente escravizadas. Na atualidade, a violência cumpre o papel de separação dessas mães e filhos

Nesse mesmo sentido Kilomba (2019) ressalta as demarcações sociais que atravessam a trajetória da muIher negra. Um exemplo direto sobre essa discussão, é o direito reprodutivo de ser mãe que é negado a mulher negra, pois esse lugar de mãe ideal é dado somente a mulher branca. Assim, quando a mãe negra perde o seu filho, existe um descredibilidade em seu sofrimento.

Lembrando do discurso de Sojouner Truth em que ela apresentava a emblemática frase "E eu não sou uma mulher?" colocando em pauta a importância das mulheres negras no feminismo, trazendo a ideia de liberdade contra ideais racistas e sexistas e reportando essa frase para o nosso contexto, além de serem destituídas de gênero, as mulheres negras também passam pela destituição da maternidade (Davis, 2016).

Partindo dessa análise, a maternidade é também um espaço político para as mães negras (Santiago, 2019), principalmente por vivenciarem a interrupção da vida dos seus filhos. Assim, além de serem reconhecidas como mulheres, também há uma busca pelo reconhecimento social de serem mães, sem que essa maternidade seja interrompida.

Assim, a morte do jovem negro chega para dar novos contornos à luta das mulheres negras. É possível correlacionar a maternidade apresentada por Santiago (2019), com o conceito de dororidade, cunhado por Piedade (2020) como elemento importante que unem as mães negras diante da Necropolítica.

As autoras Araújo e Argolo (2017) apontam para as iniciativas de enfrentamento, traçando um caminho em direção a transformar o luto em luta. Tais autoras destacam as campanhas, os movimentos sociais, os relatos para a mídia sobre o que aconteceu, a inserção ou criação de projetos que visam a superação e a busca por justiça através de sua voz e visibilidade.

Dentro desse processo podemos identificar como potência o uso dos veículos de comunicação e também os movimentos sociais, como o Movimento Mães de Maio, que de acordo com o Fundo Brasil de Direitos Humanos (2011), surgiu em 2006 após uma onda de assassinatos que se iniciou no São Paulo e se expandiu para o país. Hoje, esse movimento tem representante na maioria dos estados onde as mães se unem para compartilhar as suas experiências, discutir políticas e buscar justiça e resolução dos casos.

\section{Método}

Trata-se de uma pesquisa qualitativa do tipo documental exploratória. Este tipo de pesquisa documental engloba diversos formatos, como filmes, vídeos, sites, slides e imagens (Sá-Silva, Almeida \& Guindani, 2009). A análise de conteúdo foi utilizada como método para investigação dos relatos.

A análise de conteúdo da pesquisa baseou-se na proposta de Minayo, Deslandes, Neto e Gomes (2002). Foi realizado, através dos relatos das mulheres, o levantamento de categorias que possuíam características comuns, sendo posteriormente agrupadas, a partir, da utilização de temas que surgiram nas falas, para depois serem categorizadas para a análise.

Os relatos dessas mulheres, foram identificados mediante a busca de materiais na Plataforma Google, sendo aplicadas palavras-chaves para captura dos dados em sites e outros meios de comunicação on-line.

As palavras-chave utilizadas para a busca de relatos publicados nas mídias e meios de comunicação virtual, foram: estratégia de cuidado, grupo de mães, mães de maio, enfrentamento, grupo terapêutico, rede de apoio, recursos terapêuticos, movimento social de mães, jovem assassinado, mãe de jovem assassinado e elaboração do luto. Estas palavras foram combinadas umas com as outras e usadas para identificar postagens, publicações e notícias nesse tema.

Como critérios de inclusão, foram consideradas publicações, notícias ou postagens encontradas nos meios de comunicação online que continham o relato da mãe que teve seu filho assassinado. 
Ainda como critério de inclusão, foi realizado recorte temporal, tendo como referência 2014, ano que antecedeu a chacina no bairro do Cabula, na cidade de Salvador, que resultou em 12 mortos pela polícia e marcou a Bahia. Aquele ano foi escolhido com o intuito de apurar se já haviam relatos de mães que perderam seus filhos, até 2019, ano em que a pesquisa ocorreu.

Além disso, Salvador foi o território escolhido para compor os critérios de inclusão, por ser a capital que possui a maior população negra fora da África (Santana, 2004). E por fim, foram excluídos relatos repetidos ou que fossem das mesmas pessoas ou que não estivessem no recorte temporal dessa pesquisa. Nesse percurso foram encontrados 8 relatos distribuídos em cinco jornais online e um blog.

Para cuidado da identidade dessas mães, os seus nomes foram substituídos por nomes fictícios que pertenceram a mulheres negras que foram importantes na história do movimento negro.

Inicialmente, os relatos foram agrupados em um documento Excel para organização dos materiais. No segundo momento, realizou-se a leitura dessas falas, de forma mais aprofundada. Em seguida, houve o levantamento descritivos sobre características gerais do material, como nome da mulher, ano do assassinato, autores do assassinato, se essa mulher pertence a movimento social e a fonte onde o relato foi coletado.

Por fim, após diversas leituras dos relatos, foram desvelados temas em comuns que apareciam em cada fala. A partir desses temas, foram criadas categorias que as representassem, sendo agrupadas e analisadas.

E dessa forma, foram identificadas nos relatos, as seguintes categorias: Religiosidade que continha falas de cunho religioso, Busca por justiça, no qual as mães apresentaram a necessidade de acompanhar o desfecho do caso e responsabilização dos culpados e Percepção de mulheres negras sobre o racismo, em que as mães referem perceber o racismo que aparece em todo processo de morte e luto.

Foram encontrados materiais para análise em cinco jornais digitais, sendo eles o Bocão News, El Pais, Ponte Jornalismo, Correio da Bahia, Jornal Estado de Minas, que possuíam a notícia sobre Salvador, e um blog pessoal de uma mãe. Inicialmente onze relatos foram identificados, porém apenas oito deles estavam dentro dos critérios de inclusão. Tendo como resultado, foram encontrados um relato no ano de 2014, dois em 2015, dois em 2017 e três em 2019, sendo totalizado oito relatos conforme, mostra a Tabela 1.

Tabela 1. Categorização dos Dados

\begin{tabular}{lllll}
\hline Nome & $\begin{array}{l}\text { Ano do } \\
\text { assassinato }\end{array}$ & $\begin{array}{l}\text { Autores do } \\
\text { assassinato }\end{array}$ & $\begin{array}{l}\text { Movimento } \\
\text { Social }\end{array}$ & $\begin{array}{l}\text { Veículos de } \\
\text { Comunicação }\end{array}$ \\
\hline Dandara & 2014 & Policiais & Sim & Ponte Jornalismo \\
Anastácia & 2015 & Policiais & Não & El País \\
Vênus & 2015 & Desconhecido & Não & El País \\
Tereza & 2017 & Desconhecido & Não & Bocão News \\
Zeferina & 2017 & Desconhecido & Não & Estado de Minas \\
Acotirene & 2019 & Policias & Não & Blog \\
Mahim & 2019 & Policiais & Não & Correio da Bahia \\
Lelia & 2019 & Policiais & Não & Correio da Bahia \\
\hline
\end{tabular}




\section{Resultados e Discussões}

A realização da pesquisa na Plataforma Google apresenta limites na identificação de documentos para a pesquisa. Essa plataforma disponibiliza publicações de acordo com patrocínio, quantidade de acessos e vários outros parâmetros que interferem nas buscas dentro da plataforma, assim, é possível ter ficado de fora desta pesquisa outros relatos que poderiam contribuir para essa pesquisa.

Nesse sentido, a pesquisa se justifica por ser de caráter qualitativo e exploratório. E não teve a pretensão de abranger um universo de representatividade numérica, mas apreender aspectos da construção subjetiva de discursos de mães que perderam seus filhos, podendo ser explorado outros aspectos e universos por outras pesquisas.

A escassez de falas coletadas pode estar relacionada, além dos aspectos supracitados, também pode estar associada com a dor da perda e o medo de exposição, visto que, na maioria dos casos, a polícia militar tem algum tipo de ligação com o assassinato. Esse silêncio reafirma o quanto a mulher negra passa por processos de descredito, falta de empatia e até culpabilização de seu sofrimento, interferindo diretamente na elaboração dessa perda.

No que diz respeito às mães, somente uma delas pertence a movimento social, sendo este o movimento Mães de Maio, demonstrando o quanto a união e acolhida ajudam para que ela continue caminhando e buscando justiça. Assim, participar de movimentos sociais pode funcionar como um fator de proteção para a perda de um filho por assassinato (Bousso, Frizzo, Santos \& Bousso, 2014; Araújo \& Argolo 2017; Costa, Njaine \& Schenker, 2017; Domingues, Dessen \& Queiroz, 2015).

Nesse contexto é possível corroborar e sustentar com a ideia de que o luto é sim, um fenômeno político e social, por considerar que esse processo não é validado tanto pela sociedade quanto pelo Estado (Alencar, 2011; Araújo \& Argolo, 2017; Madeira \& Gomes, 2018), principalmente por ser atravessado por aspectos de gênero, raça e classe, que são socialmente construídos e que marcam a trajetória de mulheres negras periféricas, que são diferente de outras mulheres.
A partir dos resultados também é possível pensar que os veículos de comunicação em massa ainda têm, no âmbito social uma magnitude considerável, mesmo existindo outros meios de comunicação (Bousso, Frizzo, Santos \& Bousso, 2014), já que é foram nos noticiários que encontramos grande parte do material desta pesquisa

Todos os materiais coletados se referem a acontecimentos ocorridos nos bairros periféricos da cidade de Salvador. A faixa etária dos jovens assassinados é de 15 a 26 anos de idade, sendo todos do sexo masculino, corroborando com o perfil que também aparecem nos dados do IPEA (2019; 2020). O que nos faz refletir sobre o aspecto de geração e gênero como dois fatores importantes para o genocídio.

Assim, temos uma juventude negra sendo exposta a violência extrema, comprometendo o seu desenvolvimento e tendo suas histórias atravessadas pelo racismo. Essa geração é posta diante de um cenário de extermínio que prejudica a manutenção da sua existência, impossibilitando a continuação de linhagem da mesma, no momento em que esses jovens são mortos e têm suas vidas interrompidas.

Em relação ao aspecto de gênero, essa morte do homem negro reflete aspectos sócio-históricos que contribuem na construção da imagem racista deste homem como um não sujeito (Santiago,2019), um animal, destituído de alma e que produz perigo e violência em qualquer espaço que esteja, tornando-se o sujeito passível de ser sempre suspeito de cometer algo ilícito.

Essa configuração que coloca o jovem negro nesta posição é feita com o intuito de perpetuar a lógica da Necropolítica, em que Mbembe (2018) nos apresenta a guerra e o discurso do medo e terror como importantes nesse processo da morte, que pode ser percebido no contexto brasileiro através das constantes violências experienciadas dentro da periferia.

Existem três relatos no qual os responsáveis pelas mortes ainda não foram identificados. Esses casos refletem um possível desinteresse do Estado em solucionar o assassinato, desvelando um contexto de negação de direitos, silenciamentos, parcialidade nas soluções dos casos, deixando essas mães sem respostas, potencializando o sentimento de impunidade e consequentemente aumento seu sofrimento psíquico. 
Mbembe (2018) também discute sobre as diversas formas que a Necropolítica se organiza, podendo concretizar o poder da morte através, por exemplo, do Estado, grupos privados, organizações mistas. Como as drogas são criminalizadas, as intervenções policiais para combater o tráfico de drogas e o crime organizado produzem mais violências e são a sentença de morte para os jovens negros.

O contexto de guerra constrói um sujeito considerado perigoso, o inimigo da sociedade, aumentando tensões e produzindo medo. Esse medo, é um fator psicossocial que Necropolítica utiliza para garantir a eficácia no matar.

Assim, o corpo negro é inscrito por discursos e representações que o direciona para a morte por serem considerados desimportantes e perigosos (Mbembe, 2018; Santiago, 2019).

\section{Categorias de Análise}

\section{A religiosidade}

A religiosidade é um fator preponderante na vida dos sujeitos por ter diversas funções sociais e contribuir na construção de sentidos, valores, modos de subjetivação e comportamentos, sendo importante para a ordenação da vida do sujeito (Murakami \& Campos, 2012).

Assim, algumas mães trazem em seu discurso a utilização da religiosidade como estratégia para lidar com a perda desse filho, o que nos leva a corroborar com a ideia de Murakami e Campos (2012) ao afirmarem que a religião é sim um elemento importante para a saúde mental, por ser constituído de subjetividade e responsável de também dar significado ao sofrimento humano.

É possível, perceber a religiosidade sendo utilizada como uma possibilidade de amparar intrapsiquicamente essas mulheres a seguir em frente, mesmo havendo bastante dor (Domingues et al. 2015). Notadamente é atribuída a figuras religiosas a função de dar encaminhamentos e até desfechos, conforme identificados nas falas:
Todo começo de noite eu choro, para aliviar. E rezo muito para ter forças para continuar. (Vênus, jornal EL País).

Eu acredito que a Justiça de Deus tarda, mas não falha (Tereza, jornal Bocão News)

É importante destacar que mesmo com a religiosidade sendo utilizada, ainda há um sofrimento com a perda. A morte abrupta e a falta de resposta produzem nessas mães efeitos diferentes de outras mortes, afetando na elaboração da perda. O sofrimento não ocorre somente pela morte do filho, mas também pela circunstância, no qual, esse jovem foi assassinado, e também por um Estado que não garante a busca e responsabilização dos culpados, restando para essas mulheres, buscarem esse direito de resposta dentro da religiosidade (Costa, Ndjaine \& Sckenker, 2017; Dalbosco, 2006).

\section{A Busca por Justiça}

Buscar os responsáveis, vê-los sendo julgados e o caso sendo resolvido foi uma outra categoria identificada no discurso por grande parte das mães. Sendo uma estratégia que pode possibilitar negociações e modificações de sentidos dessa perda (Domingues, Dessen \& Queiroz, 2015). Os depoimentos das mães, demonstram luta por justiça enquanto buscam minimamente uma reparação e desfecho, com o julgamento dos responsáveis, sendo ilustrado pela fala de Lélia:

Eu quero justiça e vou lutar por isso. A morte do meu filho não vai passar em vão. Eu quero respostas. (Lélia, jornal Correio da Bahia)

Assim, mesmo diante de um contexto que legitima a morte do filho e o envolvimento dos aparelhos de segurança nesse assassinato, o que pode colocar a sua vida em risco, essa mãe reafirma a necessidade de lutar por justiça e encontrar os culpados para que os mesmos respondam pelo que fizeram. Fazse presente a necessidade de obter um fechamento do que aconteceu e consequentemente saber que a perda do seu filho não será apenas estatística. Como pode ser visto:

Não vou desistir. Quero que paguem pelo que fizeram. Mataram ele. (Mahim, jornal Correio da Bahia). 
Se a polícia disser que meu filho era traficante, eu vou xingar de Dilma ao vereador. Eu vou exigir provas.

Nem que eu tome um tiro. Mesmo que eles estivessem fazendo coisa errada, eles não tinham direito de fazer o que fizeram. (Anastácia, jornal EL País).

E, depois disso, eles [policiais] foram agraciados. Entrando na Polícia Militar da Bahia. Eu vou continuar lutando para que haja Justiça nesse caso. Há um genocídio, na verdade, aqui na Bahia. ED é mais um desses que foi vítima dessa sociedade, dessa Polícia Militar (Dandara, jornal Ponte Jornalismo).

Mahim, Anastácia e Dandara, em suas falas, fazem-nos refletir que a polícia militar funciona dentro de uma lógica genocida, e por isso a necessidade de revelar essa prática ilícita de incriminação do corpo negro.

Nas três falas, repete-se o envolvimento direto e indireto do Estado como facilitador e até premiador dessas práticas da polícia militar, que segundo essas mães trabalham para manutenção do genocídio do jovem negro. Nesse contexto é possível perceber como as tecnologias conforme a Necropolítica.

A mulher negra surge com a sua maternidade que é ressignificada como estratégia de negociar os processos políticos, principalmente a denúncia do Estado. É nesse contexto que a mãe negra se coloca enquanto sujeito político, dando à maternidade um novo lugar, de luta e resistência.

Dandara é a única mãe vinculada ao movimento social Mães de Maio. Estar associada e atuante dentro de um movimento e sempre falar sobre essa morte também para as mães de Maio da Bahia e de outros estados pode ser analisada como estratégias utilizadas por ela para poder enfrentar não somente a dor da perda, mas também a dor da impunidade, assim, Dandara apresenta em sua fala uma grande força que a movimenta.

Essa luta por justiça, reparação não é atual. Davis (2016) em seu contexto apontava para os reflexos do regime escravocrata e seus aspectos para mulheres negras estadunidenses, e Akotirene (2019) reafirma essas questões apresentadas por Angela Davis já no contexto brasileiro, demarcando o quanto a estrutura do racismo brasileiro afoga a subjetividade da muIher negra reverberando em todas as dimensões da sua vida, inclusive a maternidade.
O filho dessas mulheres, tem sua vida interrompida pela Necropolítica, que apresenta estratégias bem visíveis de como funciona. Um claro exemplo disso é a fala do Governador do Estado da Bahia sobre a Chacina do Cabula que ocorreu em 2015, e vitimou doze jovens negros. O Governador comparou os policiais como jogadores de futebol, afirmando:

É como um artilheiro em frente ao gol que tenta decidir, em alguns segundos, como é que ele vai botar a bola dentro do gol, pra fazer o gol[...] Depois que a jogada termina, se foi um golaço, todos os torcedores da arquibancada irão bater palmas e a cena vai ser repetida várias vezes na televisão. Se o gol for perdido,

o artilheiro vai ser condenado, porque se tivesse chutado daquele jeito ou jogado daquele outro, a bola teria entrado (Fragmento retirado do jornal Correio da

Bahia, 2015).

É possível ver o quanto o corpo negro é transformado em objeto e destituído de subjetividade, assim, quando não há subjetividade não há sujeito, e se não há sujeito também não haverá existência. Essa negação do outro reflete no sofrimento diante da perda do seu filho e também na sua própria subjetividade enquanto mulher e mãe negra, que dentro dessa proposição de quem tem subjetividade e sofrimento silenciado.

As ações desenvolvidas nas operações policiais geralmente envolvem intervenções menos cuidadosas, e resultados mais desastrosos em lugares periféricos. Assim de acordo com Mbembe (2018) “[...] a execução em série transformou-se em um procedimento puramente técnico, impessoal, silencioso e rápida" (p.21).

\section{Percepções das Mães Negras sobre o Racismo}

Nos relatos, ressaltaram-se aspectos relacionados à indignação e frustração no que diz respeito às práticas da polícia militar baiana, que também são importantes para análise. A perversidade praticada dentro da periferia (Santiago, 2019) é explicitada nas falas dessas mães. Assim, camuflados pelos discursos e estratégias de repressão ao tráfico de drogas, os autores dos assassinatos forjam cenários para não serem culpabilizados (Machado \& Noronha, 2002), como podemos ver no relato a seguir: 
Nem que eu tome um tiro. Mesmo que eles estivessem fazendo coisa errada, eles não tinham direito de fazer o que fizeram. (...) a crueldade é o que mais me dói". (Akotirene, retirado de Blog).

É perceptível neste relato o quanto a maternidade da mãe negra é interrompida de forma perversa. O que corrobora com a literatura, que discute sobre esse direito de maternar que é negado desde a escravidão e que atualmente tem novas configurações e desta forma, ao invés desse jovem ser escravizado é assassinado (Araújo \& Argolo 2017; Kilomba, 2019).

"Os amigos deles correram, mas o meu menino não, porque eu sempre dizia para ele que, quando a polícia chegasse, ele não deveria correr. Foi o que ele fez, mas não adiantou. Mataram ele". Eles disseram para o meu filho: 'você vai morrer, ... vai morrer, prepara para morrer' e atiraram. Depois, encontramos o corpo dele numa vala, perto de onde o policial aparece no vídeo.

Eles mataram um menino que não se envolvia com nada, que não bebia, não fumava, nunca parou numa delegacia" (Mahim, jornal Correio da Bahia).

"Meu filho parou. Ele não correu. Porque a gente sempre ensinou a ele: se você ver uma viatura, não corra, peça para te levar na sua casa. Mas não, eles mandaram meu filho se jogar no chão: 'se joga no chão .... Foi isso que disseram pro meu filho. Tem gente que viu. Meu filho se jogou no chão, está com o rosto arranhado" (Lélia, jornal Correio da Bahia).

Nessas duas falas percebe-se o quanto o racismo se expressa e atravessa a história deste povo (Damasceno \& Zanello, 2018; Dupas \& Romero 2018), que mesmo educando os seus filhos, para protegêlos das injustiças que os mesmos podem passar, não conseguem livrá-los das artimanhas do racismo estrutural e institucional que se expressa na violência.

É nesse processo que é possível visualizar o que Akotirene (2019) aponta como atravessamentos de gênero, raça, classe e território na experiencia de perda dessas mulheres, criando um contexto de culpabilização em que elas carregam fracasso de ter perdido o filho. Porém, esse fracasso na verdade é das políticas públicas e do Estado, que cria um cenário letal de guerra às drogas e que acaba vitimando adolescentes e jovens negros.

Por isso ainda que desenvolva práticas de educação familiar sobre como proceder diante de uma abordagem policial, não blinda o jovem negro de ser assassinado. Refletir e afastar a culpabilização individual dessas mães para consigo mesmas é importante para a construção do autocuidado dentro desse processo de perda e racismo.

Santiago (2019) já nos apresenta o lugar coletivo de ser mãe que é construído socialmente, mostrando que nos discursos de mães negras que perderam seus filhos, existem um compartilhamento de sentimento comum, que é a dor da perda e também a ideia de amor materno, sendo esses dois elementos importantes para a formação de redes de cuidado e luta. Esses discursos tanto do amor materno, quanto de dor, podem ser percebidos nos relatos das mulheres dessa pesquisa.

Em todas as falas foi possível analisar o quanto essas mães não estão alienadas diante do racismo, do machismo e do classicismo como fatores condicionantes para o silenciamento diante da morte dos seus filhos. Apresentando, mesmo com muito sofrimento, a vontade de confrontar o Estado e de buscar respostas.

É dentro desse movimento de busca por justiça, e desses sofrimentos, que são históricos, que a dororidade se inscreve nessas mulheres negras como uma dor que se transforma na possibilidade de construção de união, relembrando que os direitos da população negra só foram conquistados a partir de muita luta (Piedade, 2017).

Historicamente as mulheres negras buscam espaço enquanto mulher e mãe na sociedade, construindo trajetórias coletivas como o movimento feminista negro. É possível perceber um alinhamento no discurso dessas mães com a história do movimento feminista, no qual essas mães nos apresentam as categorias identitárias de raça, gênero e classe e a dororidade através dos seus discursos. 


\section{Considerações Finais}

Foi possível, conhecer algumas formas de enfrentamentos utilizadas por essas mães negras após a morte dos seus filhos. Bem como identificar, através dos relatos, um contexto marcado por extrema violência, violação de direitos e silenciamentos, potencializando mais ainda a vulnerabilidade social e de saúde.

É perceptível o quanto essas mulheres ainda não utilizam como referência a Rede de Atenção Psicossocial, no qual não aparece em seus relatos. Assim, algumas hipóteses podem ser levantadas, como a necessidade de fortalecimento e divulgação da Rede Psicossocial para essas mulheres, como estratégia de cuidado. Também pode haver o não reconhecimento, pertencimento ou até dificuldade de acesso a essa tecnologia de cuidado, que pode ser importante para a promoção do cuidado em saúde mental.

Foi possível ter contato com aspectos que revelam dor, revolta, frustração, mas também ressignificação e união dentro dessa realidade, sendo um dado significativo para percebermos essas mães para além da estagnação após a perda do seu filho. E também reconhecer o quanto a maternidade ainda é um espaço de luta para essas mulheres negras.

As mães negras, precisam constantemente demarcar pra sociedade que os jovens que foram assassinados eram sujeitos, tinham uma vida, tinham uma família, e que essa família foi desfeita com essa morte abrupta. Essas mães denunciam o seu sofrimento silenciado tanto pela sociedade, quanto pelo Estado, mostrando o quanto ainda estão longe de viverem em um país democrático e livre do racismo.

Nesse contexto os veículos de comunicação também contribuem para a construção de narrativas que descredibilizam esse sofrimento ao associar o jovem assassinado a atividades criminosas, potencializando a falta de empatia diante do fato, além de reforçarem estereótipos preconceituosos que estampam as manchetes, potencializando a sua responsabilidade na manutenção do racismo brasileiro.
Como limitação deste trabalho, admite-se a falta de contato direto com essas mães, ficando-se à mercê do material publicado pela própria mídia, responsável por mostrar essa vivência, com os recortes e edições realizados de acordo com o que é conveniente para ao veículo externalizar. Ademais, a utilização da plataforma Google também é uma outra limitação do trabalho, por considerar que a busca somente neste espaço fica limitado a resultados que a própria plataforma, junto com patrocinadores, se dispõe a divulgar.

Além disso, existe uma necessidade de produzir mais pesquisas que promovam o contato direto com essas mães e que investiguem mais sobre esse sofrimento e seus desdobramentos na sua saúde mental.

Em suma, investigar os relatos dessas mães negras possibilitou conhecer algumas estratégias, e também trazer à tona essas mulheres que foram suprimidas para atrás dos dados estatísticos sobre a morte dos seus filhos, dando novos contornos a discussão da problemática da violência urbana.

\section{Contribuições das autoras}

Souza LG participou da concepção, delineamento, pesquisa online dos dados, análise dos dados da pesquisa, interpretação dos resultados e redação do artigo. Castelar M participou da a concepção, discussão dos dados, orientação para revisões. Santana KSO e Souto VS participaram da concepção, análise e revisões do texto. Todas as autoras participaram ativamente da elaboração do presente artigo.

\section{Conflitos de interesses}

Nenhum conflito financeiro, legal ou político envolvendo terceiros (governo, empresas e fundações privadas, etc.) foi declarado para nenhum aspecto do trabalho submetido (incluindo, mas não se limitando a subvenções e financiamentos, participação em conselho consultivo, desenho de estudo, preparação de manuscrito, análise estatística, etc.). 


\section{Referências}

Adorno, L. (2016). 'Decidiram fazer o holocausto do meu filho', diz mãe de Davi Fiuza. Ponte. https://ponte.org/decidiramfazer-o-holocausto-do-meu-filho-diz-mae-de-davi-fiuza/

Akotirene, C. (2019). Interseccionalidade. Editora Jandaíra.

Acevedo, C. R., Nohara, J., \& Ramuski, C. L. (2010). Relações raciais na mídia: Um estudo no contexto brasileiro. Revista Psicologia Política, 10(19), 57-73. https://docplayer.com. br/74228632-Relacoes-raciais-na-midia-um-estudo-nocontexto-brasileiro-racial-relations-in-the-media-a-studyin-the-brazilian-context.html.

Araújo, R., \& Argolo, M. M. (2018) Construções de gênero das mulheres/mães negras no contexto da violência policial contra adolescentes e jovens. Dikè - XVII - Publicação Semestral- 2017.2. Revista Jurídica do Curso de Direito da UESC, 17. http://periodicos.uesc.br/index.php/dike/article/ view/1910

Alarcão, A. C. J., Carvalho, M. D. B., \& Pelloso, S. M. (2008). A morte de um filho jovem em circunstância violenta: Compreendendo a vivência da mãe. Revista LatinoAmericana de Enfermagem, 16(3), 341-347. https://doi. org/10.1590/S0104-11692008000300002

Almeida, S. (2018). O que é racismo estrutural? Pólen.

Basso, L. A., \& Wainer, R. (2011). Luto e perdas repentinas: contribuições da terapia cognitivo-comportamental. Revista Brasileira de Terapias Cognitivas, 7(1), 35-43. http://pepsic.bvsalud.org/scielo.php?script=sci_ arttext\&pid=S1808-56872011000100007

Bousso, R. S., Ramos, D., Frizzo, H. C. F., Santos, M R., \& Bousso, F. (2014). Facebook: Um novo locus para a manifestação de uma perda significativa. Psicologia USP, 25(2), 172-179. https://doi.org/10.1590/0103-656420130022

Barros, J. P. P., Nunes, L. F., Sousa, I. S., \& Cavalcante, C. O. B. (2019). Criminalização, extermínio e encarceramento: expressões necropolíticas no Ceará. Revista Psicologia Política, 19(46), 475-488. http://pepsic.bvsalud.org/scielo. php?script=sci_arttext\&pid=S1519-549X2019000300008\&l $n g=p t \& t$ lng $=p t$

Costa, D. H., Njaine, K., \& Schenker, M. (2017). Repercussões do homicídio em famílias das vítimas: uma revisão da literatura. Ciência \& Saúde Coletiva, 22(9), 3087-3097. https://dx.doi.org/10.1590/1413-81232017229.18132016

Costa, D. H., Schenker, M., Njaine, K., \& Souza, E. R. (2017). Homicídios de jovens: os impactos da perda em famílias de vítimas. Physis: Revista de Saúde Coletiva, 27(3), 685-705. https://dx.doi.org/10.1590/s0103-73312017000300016
Correio (2015). 'É como um artilheiro em frente ao gol', diz Rui Costa sobre ação da PM com doze mortos no Cabula. Correio. https://www.correio24horas.com.br/noticia/nid/e-comoum-artilheiro-em-frente-ao-gol-diz-rui-costa-sobre-acaoda-pm-com-doze-mortos-no-cabula/

Davis, A. (2016). Mulheres, raça e classe (H. R. Candiani, Trad.). Boitempo.

Damasceno, M. G., \& Zanello, V. M. L. (2018). Saúde mental e racismo contra negros: Produção bibliográfica brasileira dos últimos quinze anos. Psicologia: Ciência e Profissão, 38(3), 450-464. https://dx.doi.org/10.1590/198237030003262017

Dias, E., \& Amorim, G. (2019). 'Atiraram pelas costas e pisaram na cabeça', diz familiar de estudante morto pela PM. Correio. https://www.correio24horas.com.br/noticia/nid/atirarampelas-costas-e-pisaram-na-cabeca-diz-familiar-deestudante-morto-pela-pm/

Domingues, D. F. (2010). Homicídio juvenil por arma de fogo: luto, enfrentamento e reorganização na família vitimada. (Dissertação de Mestrado, Universidade de Brasília). http://repositorio.unb.br/bitstream/10482/6684/3/2010_ DanielaFontouraDomingues.pdf

Domingues, D. F., Dessen, M. A., \& Queiroz, E.(2015). Luto e enfrentamento em famílias vitimadas por homicídio. Arquivos Brasileiros de Psicologia, 67(2), 61-74. http://pepsic. bvsalud.org/scielo.php?script=sci_arttext\&pid=S1809$52672015000200006 \&$ lng $=p t$

Dupas, E., \& Romero, T. G. (2018). Violência no Brasil: As cores que morrem. Revista Libertas. Direito UFOP, 3(2), 1-9. https:// periodicos.ufop.br:8082/pp/index.php/libertas/article/ view/420

Estado de Minas (2015). Na Bahia, mãe tenta se recuperar da morte dos 3 filhos. Estado de Minas. https://www.em.com.br/app/ noticia/nacional/2015/01/28/interna_nacional,612573/ na-bahia-mae-tenta-se-recuperar-da-morte-dos-3-filhos. shtml

Fernandes, V. B., \& Souza, M. C. C. C. (2016). Identidade negra entre a exclusão e a liberdade. Revista do Instituto de Estudos Brasileiros, (63), 103-120. https://dx.doi. org/10.11606/issn.2316-901X.v0i63p103-120

Faria, A. A. C., \& Barros, V. A. (2011). Tráfico de drogas: uma escolha entre opções escassas. Psicologia \& Sociedade, 23(3), 536-544. https://doi.org/10.1590/S010271822011000300011

Instituto de Pesquisa Econômica Aplicada (2018). Atlas da violência. https://www.ipea.gov.br/portal/index.php?option=com content\&view=article\&id=33410\&ltemid $=432$ 
Instituto de Pesquisa Econômica Aplicada (2019). Atlas da violência. https://www.ipea.gov.br/atlasviolencia/download/19/atlasda-violencia-2019

Instituto de Pesquisa Econômica Aplicada (2020). Atlas da violência. https://www.ipea.gov.br/atlasviolencia/download/24/atlasda-violencia-2020

Jovchelovitch, S. (2004). Psicologia social, saber, comunidade e cultura. Psicologia \& Sociedade, 16(2), 20-31. https://doi. org/10.1590/S0102-71822004000200004

Kilomba, G. (2019). Memórias da plantação: episódios de racismo cotidiano. Cobogó.

Lemos, F. C. S., Aquime, R. H. S., Franco, A. C. F., \& Piani, P. P. F. (2017). O extermínio de jovens negros pobres no Brasil: práticas biopolíticas em questão. Revista Pesquisas e Práticas Psicossociais, 12(1), 164-176. http://seer.ufsj.edu. br/index.php/revista_ppp/article/view/1912

Longo, I. S. (2012). O Estigma de Três Ps: Pessoa Pobre, Negra, da Periferia. A Visão dos Adolescentes da Comunidade Heliópolis. Anais do Primeiro Colóquio Internacional Culturas Jovens Afro-Brasil América: Encontros e Desencontros, Faculdade de Educação da Universidade de São Paulo, São Paulo, SP, Brasil. http://www.proceedings.scielo.br/pdf/ cjaba/n1/17.pdf

L.S.S. (2017). Do luto para a luta. Blog. http://dolutoparaluta. blogspot.com/2012/05/maes-que-perderam-seus-filhospara.htm

Luiz, B. (2019). Chacina do Cabula completa quatro anos, e familiares fazem homenagem às vítimas. Bocão News. https://www.bnews.com.br/noticias/policia/ policia/227687, chacina-do-cabula-completa-quatro-anose-familiares-fazem-homenagem-as-vitimas.html

Machado, E. P., \& Noronha, C. V. (2002). A polícia dos pobres: violência policial em classes populares urbanas. Sociologias, (7), 188-221. https://dx.doi.org/10.1590/S151745222002000100009

Marreiro F. (2016a). As mães do Cabula, na Bahia: à procura de resposta por seus mortos. El País. https://brasil.elpais.com/ brasil/2015/05/05/politica/1430854639_508994.html
Marreiro F. (2016b). As mães do Cabula, na Bahia: à procura de resposta por seus mortos. El País https://brasil.elpais.com/ brasil/2015/05/05/politica/1430854639_508994.html

Minayo, M. C. S., Deslandes, S. F., \& Gomes, R. (2016). Pesquisa social: Teoria, método e criatividade. Vozes.

Mbembe, A. (2018). Necropolítica biopoder soberania estado de exceção política de morte (R. Santini, Trad.). N-1 edições.

Movimento Mãe de Maio (2011). Mães de maio do luto à luta. Debora Maria e Danilo Dara. https://fundobrasil.org.br/ wp-content/uploads/2016/07/livro-maes-de-maio.pdf

Murakami, R., \& Campos, C. J. G. (2012). Religião e saúde mental: desafio de integrar a religiosidade ao cuidado com o paciente. Revista Brasileira de Enfermagem, 65(2), 361-7. http://dx.doi.org/10.1590/S0034-71672012000200024

Madeira, Z., \& Gomes, D. D. O. (2018). Persistentes desigualdades raciais e resistências negras no Brasil contemporâneo. Serviço Social \& Sociedade, (133), 463-479. https://dx.doi. org/10.1590/0101-6628.154

Piedade, V. (2017). Dororidade. Nós.

Santana, A. (2004). Salvador: a luta pela reparação dos negros. Estudos Avançados, 18(50), 147-152. https://dx.doi. org/10.1590/S0103-40142004000100015

Santiago, V. (2019). A maternidade como resistência à violência de Estado. Cadernos Pagu, (55), e195511. https://dx.doi.org/10 $.1590 / 18094449201900550011$

Sá-Silva, J. R., Almeida, C. D., \& Guindani, J. F. (2009) Pesquisa documental: pistas teóricas e metodológicas. Revista Brasileira de História e Ciências Sociais, 1(1), 1-15. Recuperado de https://www.rbhcs.com/rbhcs/article/ viewFile/6/pdf

Wendel B. (2019). 'Quero que eles paguem', diz mãe de jovem morto em São Marcos sobre PMs. Correio. https://www. correio24horas.com.br/noticia/nid/quero-que-elespaguem-diz-mae-de-jovem-morto-em-sao-marcos-sobrepms/ 